\title{
Carcinoid Heart Disease: Pathophysiology, Pathology, Clinical Manifestations, and Management
}

\author{
Chengyue Jin Ajay Nair Sharma Balasingam Thevakumar Muhammad Majid \\ Shahad Al Chalaby Nene Takahashi Ashraf Tanious Aro Daniela Arockiam
}

Neil Beri Ezra A. Amsterdam

Division of Cardiovascular Medicine, Department of Internal Medicine, University of California (Davis)

Medical Center, Sacramento, CA, USA

\section{Keywords}

Carcinoid - Carcinoid heart disease - Carcinoid syndrome -

Pathophysiology · Management

\begin{abstract}
Carcinoid heart disease (CHD) is a rare and potentially lethal manifestation of an advanced carcinoid (neuroendocrine) tumor. The pathophysiology of $\mathrm{CHD}$ is related to vasoactive substances secreted by the tumor, of which serotonin is most prominent in the pathophysiology of CHD. Serotonin stimulates fibroblast growth and fibrogenesis, which can lead to cardiac valvular fibrosis. CHD primarily affects right heart valves, causing tricuspid and pulmonic regurgitation and less frequently stenosis of these valves. Left heart valves are usually spared because vasoactive substances such as serotonin are enzymatically inactivated in the lung vasculature. The pathology of CHD is characterized by plaque-like deposition of fibrous tissue on valvular cusps, leaflets, papillary muscles, chordae, and ventricular walls. Symptomatic CHD usually presents between 50 and 70 years of age, initially as dyspnea and fatigue. Echocardiography is the mainstay of imaging and demonstrates thickened right heart
\end{abstract}

valves with limited mobility and regurgitation. Treatment focuses on control of the underlying carcinoid syndrome, targeting subsequent valvular heart disease and managing consequent heart failure. Surgical valve replacement and catheter-directed valve procedures may be effective for selected patients with CHD.

(c) 2020 S. Karger AG, Basel

\section{Introduction}

Carcinoid syndrome is a rare endocrine disorder related to the effects of vasoactive substances produced by carcinoid tumors, the most prominent of which is serotonin (5-hydroxytryptamine) [1-4]. Serotonin stimulates intestinal secretion and motility and inhibits intestinal absorption [4]. These neoplasms primarily arise from enterochromaffin cells of endocrine and nervous system origin; the great majority of the tumors is benign, and $<10 \%$ are malignant $[3,5,6]$. The incidence of carcinoid tumors in the general population is approximately $1-5 / 100,000$ persons $[1,3,7,8]$. Carcinoid tumors are most commonly located in the gastrointestinal tract (midgut carcinoid), 
Table 1. Types of carcinoid disease

\begin{tabular}{lll}
\hline Type & Characteristics & Biomarker profile \\
\hline Carcinoid tumor (NET) & Location: GI, bronchus and GU tract & $\uparrow$ Serum 5-HT and $\uparrow$ 24-h urine 5-HIAA levels \\
\hline Carcinoid syndrome & NET with metastasis, mainly to liver & $\begin{array}{l}\uparrow \uparrow \text { Serum 5-HT and } \uparrow \uparrow \text { 24-h urine 5-HIAA levels } \\
+ \text { systemic manifestations }\end{array}$ \\
\hline Carcinoid heart disease & Carcinoid syndrome + cardiac involvement & Same as carcinoid syndrome + $\uparrow$ NT-pro-BNP \\
\hline
\end{tabular}

$\uparrow$, elevated; $\uparrow$, markedly elevated; NET, neuroendocrine tumor; GI, gastrointestinal; GU, genitourinary; 5-HT, serotonin (5-hydroxyltryptamine); 5-HIAA, 5-hydroxy indole acetic acid; NT-proBNP, N-terminal pro-brain natriuretic peptide. ${ }^{1}$ In heart failure.

Table 2. Carcinoid heart disease pathology

\begin{tabular}{lll}
\hline Cardiac involvement & Pathology & Symptoms and signs \\
\hline Tricuspid valve (TV) & $\begin{array}{l}\text { Fibrosis; thickened and fused commissures, } \\
\uparrow \text { Mobility } \\
\text { Regurgitation/stenosis }\end{array}$ & $\begin{array}{l}\text { Exertional dyspnea, fatigue, and symptoms of RHF; } \\
\text { edema, ascites, pleural effusion; } \uparrow \text { JVP, prominent V } \\
\text { waves and pan-systolic murmur of TR; less frequently, } \\
\text { diastolic murmur of TS }\end{array}$ \\
\hline Pulmonic valve & Same as TV & $\begin{array}{l}\text { Early diastolic murmur of PR; less frequently, systolic } \\
\text { murmur of PS }\end{array}$ \\
\hline Aortic valve $(<10 \%$ of cases $)$ & Same as TV, $2^{\circ}$ to atrial $\mathrm{R} \rightarrow \mathrm{L}$ shunt & Murmur of AS/AI \\
\hline Mitral valve $(<10 \%$ of cases $)$ & Same as TV, $2^{\circ}$ to atrial $\mathrm{R} \rightarrow \mathrm{L}$ shunt & Murmur of MS/MR \\
\hline Myocardium $(<5 \%$ of cases $)$ & $\begin{array}{l}\text { Carcinoid metastases to myocardium } \\
\text { (ventricles and septum) }\end{array}$ & Heart failure due to restrictive cardiomyopathy \\
\hline
\end{tabular}

$\uparrow$, elevated; RHF, right heart failure; JVP, jugular venous pulse; R, right; L, left; AS, aortic stenosis; AI, aortic incompetence; MS, mitral stenosis; MR, mitral regurgitation; PR, pulmonic regurgitation; PS, pulmonic stenosis; TR, tricuspid regurgitation; TS, tricuspid stenosis.

bronchus (foregut carcinoid), and genitourinary tract (hindgut carcinoid) [3, 7]. The term "carcinoid" was coined in 1907 by the German pathologist, Siegfried Oberndorfer, who discovered and named the tumor "karzinoid" or "carcinoma-like," to describe the unique behavior of a benign tumor despite a malignant microscopic appearance $[3,7]$. The World Health Organization redefined "carcinoid" in 2000 with the preferred term: neuroendocrine tumor (NET; Table 1).

Carcinoid syndrome (Table 1) is most common in patients with tumor metastases to the liver, but it can also occur in localized disease $[1,3]$. Carcinoid heart disease (CHD; Table 1) is an uncommon presentation of carcinoid syndrome, but it does eventually occur in a majority of patients with the syndrome, and it is the major cause of morbidity and mortality in these patients $[2,3,6]$. During the past 20 years, advances in diagnosis and treatment have provided improved therapeutic approaches with the potential to decrease the toll of death and disability from CHD $[6,8]$.

\section{Pathology and Pathophysiology}

Carcinoid tumors of midgut origin usually present as classic carcinoid syndrome, whereas the syndrome is rare in tumors of hindgut and foregut origin [3,9]. CHD primarily affects the right heart valves with tricuspid and pulmonic regurgitation and stenosis, because vasoactive substances such as serotonin are enzymatically inactivated in the lung vasculature preventing transport to the left heart (Table 2). Therefore, left-sided disease occurs in $<10 \%$ of patients and is almost always associated with a right-to-left intracardiac shunt at the atrial level $[2,6]$. In 
the rare cases in which shunts are not a factor, the underlying etiology is often primary bronchopulmonary carcinoid disease or high serotonin levels due to poorly controlled carcinoid syndrome [10].

The symptoms of carcinoid syndrome are caused by excessive secretion of vasoactive substances produced by NETs, of which serotonin is the primary agent [2-4]. Other neurotransmitters play variable pathophysiologic roles and include prostaglandins, histamine, tachykinin, and kallikrein $[6,11-13]$. Serotonin is a monoamine neurotransmitter derived from tryptophan. It is found in enterochromaffin cells in the gastrointestinal tract, where it regulates intestinal smooth muscle function, and in neurons of the central nervous system, where it influences mood and sleep $[4,5]$. The NET is typically located in the gastrointestinal tract; because serotonin undergoes degradation in the liver by hepatic monoamine oxidase, symptoms do not develop until metastases to the liver have significantly impaired hepatic function [11, 13]. Rarely, primary ovarian carcinoid tumors can also cause $\mathrm{CHD}$, in which serotonin is thought to reach the systemic circulation directly, bypassing the portal circulation and liver via the ovarian veins $[5,11]$. Enzymatic inactivation of serotonin by pulmonary monoamine oxidase in lung vasculature protects left-sided cardiac structures $[6$, 13].

Serotonin can stimulate fibroblast growth and fibrogenesis, which may lead to cardiac valvular fibrosis (Table 2) and peritoneal fibrosis $[5,6,12]$. The valvular lesions produced by high circulating serotonin levels are similar to those of ergot-alkaloid derivatives or (dex)fenfluramine [12-14]. The role of serotonin in the development of CHD is supported by markedly elevated levels (2- to 4-fold above normal) of circulating serotonin in those with the disease. Additionally, urinary 5-hydroxyindole acetic acid (5-HIAA), the major metabolite of serotonin, is also elevated in patients with CHD compared to carcinoid patients without cardiac involvement (Table 1) [6,7]. A high level of circulating serotonin is associated with increased transforming growth factor- $\beta$ latency-associated peptide and latent binding protein in the tissue of an involved heart valve, both of which promote fibrosis $[12,15,16]$. Serotonin receptors are present on heart valves and participate in collagen synthesis in valvular interstitial cells $[16,17]$. In experimental animal studies, long-term serotonin administration can produce morphologic and echocardiographic valvular alterations similar to those in human CHD $[16,18]$.

The pathology of right-sided CHD is characterized by plaque-like deposition of fibrous tissue on valvular cusps, leaflets, papillary muscles, chordae, ventricular walls, and occasionally on the intima of pulmonary arteries $[5,6,14$, 19] (Table 2). Tricuspid valve chordae are focally thickened and commissures often mildly fused, thus mimicking the pathology of chronic rheumatic valve disease. The downstream aspect of the pulmonary cusps and surfaces of the tricuspid leaflets are the most prominent sites of plaque formation. Plaques usually present a "stuck-on" pattern without compromising the underlying valve architecture $[6,19]$. The composition of the plaque comprises myofibroblasts, lymphocytes, mast cells, extracellular matrix (collagen, myxoid matrix, and elastin), and an overlying endothelial layer. Over $95 \%$ of those with valvular involvement have tricuspid valve disease, and approximately $90 \%$ display moderate or severe tricuspid regurgitation. In the $85 \%$ of patients with pulmonary valve disease, about $80 \%$ had regurgitation while stenosis was present in 50\% [2].

It has been reported that serotonin has a vasospastic effect on predisposed atherosclerotic coronary arteries $[20,21]$. The spasm displays a biphasic dose-dependent result causing vasoconstriction of the diseased coronary arteries and dilatation of the normal vessels. The coronary vasospastic effect can manifest clinically as variant (Prinzmetal) angina with chest pain at rest in the absence of occlusive coronary lesions. Additionally, serotonin may also reach the coronary circulation via shunting through a patent foramen ovale. Given the role of serotonin as a potent platelet activator, it may consequently induce stent thrombosis [22].

CHD may also develop as a direct result of metastases to cardiac muscle itself. One case series reported a 3.8\% incidence of metastases, with most tumors found on the ventricular septum [23]. The location of metastases dictates the presenting symptoms; solitary atrial masses may remain asymptomatic, while ventricular septal masses can result in outflow tract obstruction [24]. Ultimately, direct cardiac metastases correlate with greater tumor burden, necessitating even more stringent workup when these characteristics are found.

\section{Presentation and Physical Examination}

The typical clinical manifestations of carcinoid syndrome are the triad of cutaneous flushing, diarrhea, and bronchospasm [5-7, 12, 13]. Less frequently, cardiac valvulopathy, restrictive cardiomyopathy, and emesis occur. CHD is relatively frequent in patients with carcinoid syndrome and is responsible for considerable morbidity and 
mortality [5-7]. Onset of CHD symptoms is usually between 50 and 70 years of age and is often subtle, initially including mild exertional dyspnea and fatigue $[25,26]$. With disease progression, symptoms and signs of rightsided heart failure such as edema, ascites, pleural effusions, and cardiac cachexia may ensue. Major physical findings of $\mathrm{CHD}$ reflect regurgitation and stenosis of the tricuspid and pulmonic valves (Table 2). These include right ventricular failure, elevated jugular venous pulse with prominent $\mathrm{V}$ waves (related to tricuspid regurgitation), a pan-systolic murmur of tricuspid regurgitation accented on inspiration, early diastolic murmur of pulmonary regurgitation, pleural effusions, ascites, and edema. Less frequently, a systolic murmur of pulmonic valve stenosis or a diastolic murmur of tricuspid stenosis are audible (Table 2).

While arrythmias are a rare presenting feature of $\mathrm{CHD}$, it is necessary to consider them in patients with CHD. As a vasoactive substance, serotonin may increase sympathetic discharge and thereby cardiac excitation, resulting in multiple tachyarrhythmias [27]. This concept was supported by experimental studies, as sudden release of serotonin was associated with paroxysmal ventricular tachycardias and atrial arrhythmias [28].

5 -HIAA is the final product of serotonin metabolism and is almost exclusively excreted in the urine. Thus, measurement of 24-h urinary excretion of 5-HIAA is a useful initial diagnostic test for carcinoid syndrome because of its association with carcinoid tumor $[26,29,30]$; a urinary 5-HIAA level $>300 \mathrm{mmol} / 24 \mathrm{~h}$ helps identify individuals at risk for CHD [26, 31]. However, certain medications and foods such as plantain, pineapple, and banana can produce false-positive results in 24-h urinary excretion of 5-HIAA and thus should be avoided prior to testing $[29,32]$. Only posttreatment 5-HIAA levels independently predicted development or progression of $\mathrm{CHD}$ based on serial echocardiography, with a threshold of 100 $\mathrm{mg} / 24 \mathrm{~h}$ (normal $<25 \mathrm{mg} / 24 \mathrm{~h}$ ) [33]. False-negative serum tests for serotonin can result from use of selective serotonin reuptake inhibitors, which deplete platelet stores of the neurotransmitter [21,34], whereas false-positive tests are caused by ingestion of tryptophan/serotonin-rich foods [31-33]. Because of its lower sensitivity and specificity compared to urinary 5-HIAA, serum serotonin level is not a standard diagnostic test for carcinoid syndrome [7].

In patients with carcinoid syndrome, $\mathrm{N}$-terminal probrain natriuretic peptide (NT-pro-BNP) is a sensitive and specific marker for the presence of $\mathrm{CHD}$ in the absence of other cardiac disease $[31,35]$. NT-pro-BNP (blood) cor- related moderately well with the severity of CHD while 5-HIAA (blood) correlated only weakly, based on an echocardiographic score evaluating the severity of valvulopathies [36]. It is uniformly recommended that all patients with carcinoid syndrome undergo 6- to 12-monthly clinical evaluations for symptoms and signs of valvular disease or heart failure by measurement of serum NTpro-BNP (Table 1) $[31,36]$. Chromogranin A is an additional biomarker, albeit one with poor screening utility (sensitivity $60-90 \%$ and specificity $10-35 \%$ ) [37, 38]. It is best employed as a follow-up indicator for carcinoid recurrence, as it possesses a sensitivity of $100 \%$ for $\mathrm{CHD}$ [39].

\section{Electrocardiogram and Chest Radiograph}

In patients with $\mathrm{CHD}$, the electrocardiogram (ECG) usually has nonspecific findings such as ST-T changes, but low voltage QRS complexes may be evident in patients with advanced CHD $[26,31,40]$. ST segment elevation can occur in the setting of serotonin-induced coronary vasospasm [20]. Additional ECG findings include PR prolongation and sinus tachycardia $[26,31]$. The chest radiograph may reveal cardiomegaly with prominent right-sided chambers in $50 \%$ of patients $[25,41]$.

\section{Imaging Studies}

\section{Echocardiography}

Transthoracic two-dimensional echocardiography is the mainstay of imaging for $\mathrm{CHD}[6,31]$. Tricuspid regurgitation is typical in almost all patients with CHD and is characterized by thickened tricuspid valve leaflets, reduced mobility, and occasional immobility of tricuspid right-sided valve leaflets (Fig. 1) [25, 41, 42]. These findings are reflected in a series of 74 patients with CHD: all had tricuspid regurgitation, more than half had tricuspid valve stenosis, four-fifths had pulmonic valve regurgitation, and only $5 \%$ had left heart involvement [2]. Right ventricular volume overload and increased right heart filling pressures occur in late-stage disease. Metastatic carcinoid tumor to the heart is rare $(<5 \%)$ but occurs at a wide variety of sites, including the right ventricle, left ventricle, interventricular septum, and myocardial walls $[2,6,19]$. On echocardiography, cardiac metastases appear as homogenous, well-circumscribed, noninfiltrative masses [13,23].

Compared to two-dimensional echocardiography, three-dimensional echocardiography provides more de-
68

Cardiology 2021;146:65-73 DOI: $10.1159 / 000507847$
Jin et al. 

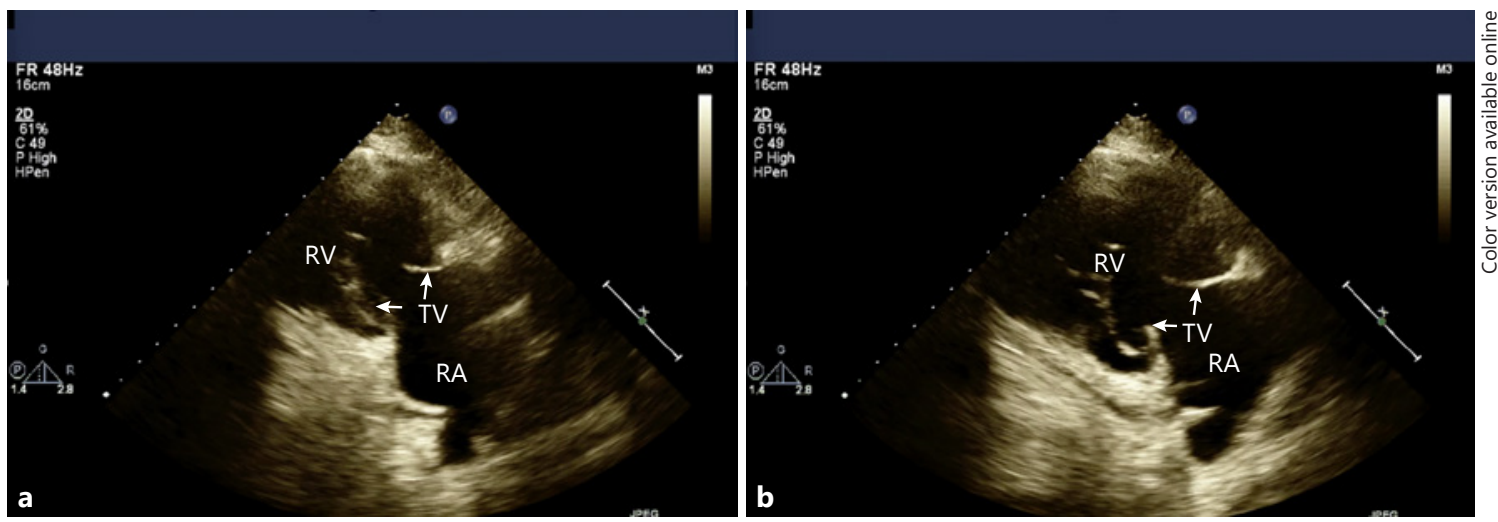

Fig. 1. Two-dimensional echocardiogram, parasternal long axis right ventricle (RV) inflow view. The tricuspid valve (TV) septal posterior leaflets (arrows) are thickened and rigid; the posterior leaflet (identified by the lower arrow) is fixed in the open position during systole (a) and diastole (b). RA, right atrium.

tailed en face visualization of valvular and subvalvular structures, and may be important in the diagnosis and evaluation of cardiac pathology, especially of pulmonic valve disease $[31,41]$. Additionally, ventricular strain determined by echocardiographic speckle tracking has demonstrated reduced ventricular function that is predictably associated with a more advanced disease state [43].

\section{CT and MRI}

These techniques can provide additional anatomic evaluation such as demonstration of right heart dilatation due to volume overload with more details than conventional imaging methods $[31,41]$. Cardiovascular MRI is a useful adjunct for accurate assessment of right ventricular systolic function and detection of myocardial metastases $[23,31]$.

\section{Treatment}

The goal of management for carcinoid syndrome and CHD is symptomatic relief and improved survival rather than definitive therapy and cure. A multidisciplinary approach should be employed to implement a treatment plan based on symptoms, stage of carcinoid tumor, histological grade, and clinical status (Fig. 2).

The somatostatin analogues, octreotide and lanreotide, have been effective in controlling symptoms of carcinoid syndrome $[3,26,31]$. Both agents are synthetic octo-amino acid peptides that bind to the somatostatin receptor subtypes 2 and 5, inhibit serotonin release, and reduce secretion of gastrointestinal hormones, such as gastrin, secretin, and cholecystokinin. Somatostatin receptors are present in NET tissue and platelets [44-46], and somatostatin analogues can thereby decrease serotonin levels. Telotristat ethyl is an oral tryptophan hydroxylase inhibitor used in combination with a somatostatin analogue for patients with inadequate response to initial management of carcinoid syndrome with a somatostatin analogue alone $[47,48]$. Recent trials have also demonstrated that everolimus can enhance progressionfree survival in patients with progressive carcinoid tumor $[49,50]$. However, deaths related to pulmonary or cardiac failure were observed more frequently in patients treated with everolimus [51].

Liver-directed therapies include surgical resection, cytoreductive therapy, radiofrequency ablation, and hepatic embolization. In a study of 42 patients, these methods were associated with a symptom-free 5-year survival of $61 \%$ in 14 patients with carcinoid syndrome and liverpredominant disease with $\mathrm{CHD}$. The latter outcome compared favorably with the $44 \%$ survival in 28 patients with carcinoid syndrome and liver-predominant disease without CHD [52].

Treatment of valvular disease and heart failure from CHD follows current guidelines [53, 54]. Carcinoid-induced ventricular tachycardia has been successfully managed with metoprolol [27]. Diuretics must be used judiciously because of the potential to reduce cardiac output in patients with right ventricular dysfunction and valve disease. Angiotensin-converting enzyme inhibitors, angiotensin II receptor blockers, renin inhibitors, and spironolactone are discontinued prior to surgical valve intervention to avert intraoperative blood pressure instability. Early valvular intervention before significant 


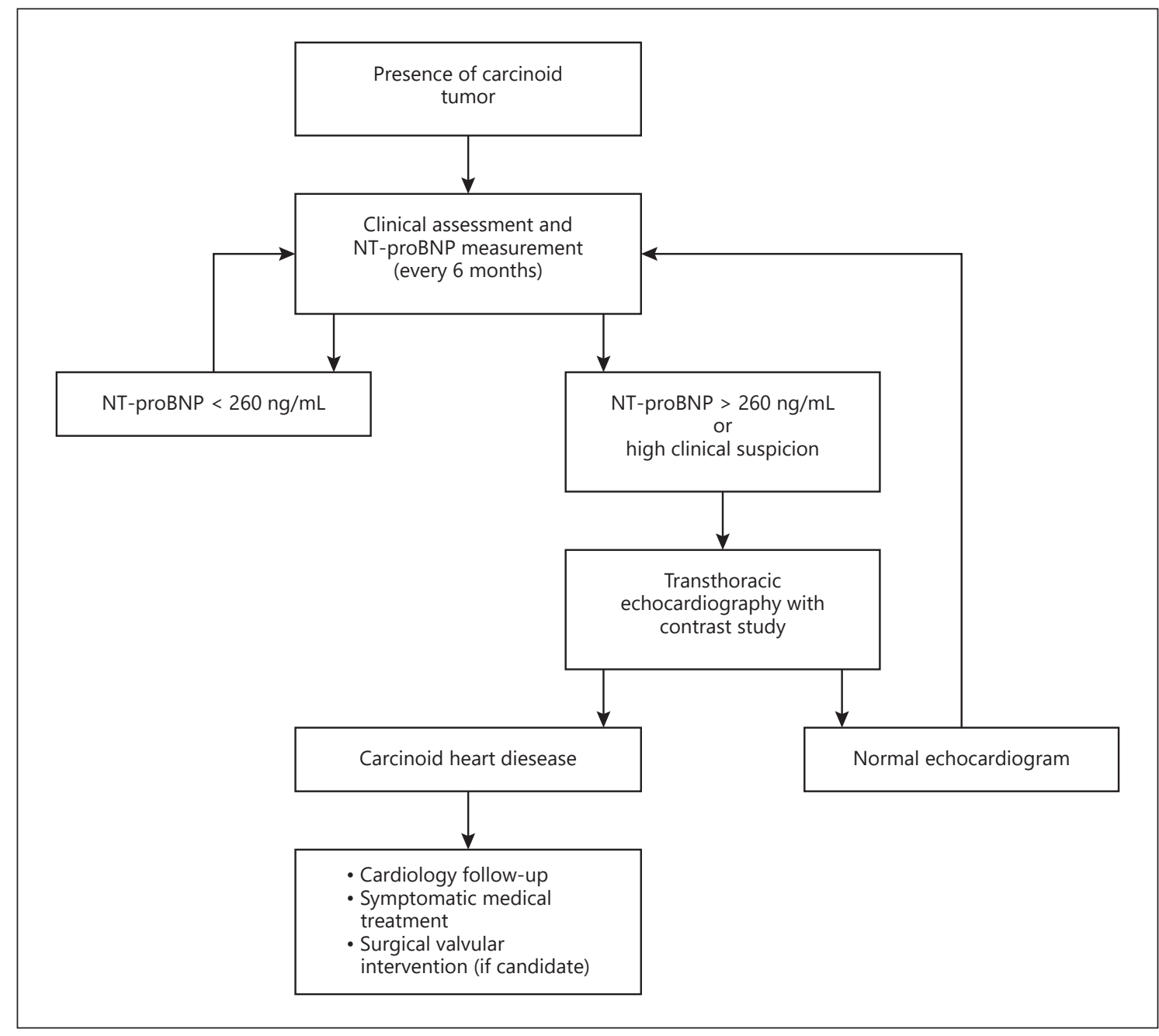

Fig. 2. Diagnostic and treatment algorithm for carcinoid heart disease.

right-sided heart failure may enhance survival $[26,55]$. Therefore, regular follow-up is mandatory with identification of patients likely to benefit from this approach.

Although there is evidence suggesting a close association between serotonin levels and presence of CHD, there is no indication that reduction of these levels can prevent or delay CHD progression [56, 57]. Only posttreatment urinary 5-HIAA levels have independently predicted development or progression of CHD based on serial echocardiography. Thus, persistent elevations in urinary 5-HIAA levels (>100 mg/24 h despite therapy) have been independently associated with development or progression of CHD [26, 30, 57-59]. In addition, somatostatin analogue, hepatic dearterialization, and chemotherapy were not associated with delay of CHD progression $[8,16,57]$.
Without proper management intervention, progressive right heart failure is inevitable. The median survival of advanced carcinoid syndrome is $12-30$ months $[26,29$, 60]. The presence of CHD with heart failure is associated with a poor prognosis and median survival of 11 months; without treatment, most patients succumb within 1 year because of progressive heart failure [26, 29, 60]. In a pooled analysis of 10 retrospective studies with a total of 193 patients, valvular surgery, largely comprising tricuspid valve replacement, was associated with improved prognosis; median postoperative survival was 58 months (28-80 months) with significant symptomatic relief in a majority of patients [61]. Operative risk was high as reflected by an average 30-day mortality of $17 \%$ (range 1-63\%). Valvular replacement surgery (usually of the tricuspid valve) has been the only approach that prolongs 
survival; mortality is generally related to tumor progression $[31,61]$.

Prior to surgery, symptoms and serum serotonin level must be well controlled. Carcinoid crisis is a life-threatening event that may be triggered by tumor manipulation during biopsy, surgery, embolization, and anesthesia that results in sudden release of an overwhelming amount of vasoactive substances. It manifests as flushing, extreme fluctuation of blood pressure, bronchoconstriction, arrhythmias, and altered mental status. Perioperative intravenous octreotide $(50-100 \mu \mathrm{g} / \mathrm{h})$ should be started $2 \mathrm{~h}$ before surgery and continued for $48 \mathrm{~h}$ postoperatively to prevent these crises $[5,16,31]$. Medications such as opioids, atracurium, and catecholamines (dopamine and epinephrine) should be avoided or dose limited during the perioperative period $[16,60]$.

Tricuspid and pulmonic valve replacement entail open heart surgery, and valve replacement is generally preferred over repair $[62,63]$. In some patients, tricuspid and pulmonic valve replacements have been undertaken simultaneously [31, 60, 62]. In patients with both left- and right-sided $\mathrm{CHD}$, triple or even quadruple valve replacement (tricuspid, pulmonary, mitral, and/or aortic) has been performed [62]. Both mechanical and bioprosthetic valves are used for these procedures, and both types are associated with value and limitations. Mechanical valves benefit from increased durability but require strict anticoagulation, increasing the risk of bleeding and reoperation [16]. Conversely, bioprosthetic valves rarely require long-term anticoagulation, but they tend to degenerate earlier due to graft failure or carcinoid-induced fibrosis [64]. For high-risk patients who are not surgical candidates, transcatheter replacement of the pulmonic and tricuspid valves has been utilized $[65,66]$. Valve-in-valve transcatheter replacement has also been employed for patients with a degenerated bioprosthetic valve.

The options for nonsurgical medical therapy have also increased. Combination therapy of paclitaxel, trastuzumab, and interleukin-12 has displayed promise in malignancies positive for human epidermal growth factor receptor $2 /$ neu expression, including carcinoid disease [67]. New therapies, specifically pasireotide, a somatostatin analogue, have helped control symptoms as efficaciously as classic octreotide treatment [68]. In patients with disease resistant to somatostatin, interferon- $\alpha$ and lutetium dotate have both reduced severity of disease as part of octreotide combination therapy $[69,70]$. Lastly, in the case of unresectable metastases from NETs such as carcinoid syndrome, yttrium-90 radioembolization of the liver has been successful in improving survival rate and tumor response [71].
CHD is a distinct yet rare form of carcinoid disease that has potentially lethal manifestations. Stemming from serotonin-induced fibroblast growth and fibrogenesis, CHD is characterized by severe valvular abnormalities and diagnosed by echocardiography. CHD most often presents between 50 and 70 years of age as severe dyspnea and fatigue. Treatment should rely on controlling the underlying carcinoid syndrome and managing subsequent valvular abnormalities and heart failure. The advent of novel nonsurgical medical therapies for the condition afford potentially promising approaches for CHD treatment.

\section{Statement of Ethics}

Ethical approval was not required given this was a review article that did not include human subjects.

\section{Conflict of Interest Statement}

None of the authors has any conflict of interest related to this work.

\section{Funding Sources}

No funding sources applicable.

\section{Author Contributions}

C.J.: primary author of the 1st submission and acquired the majority of references. A.N.S.: primary author of responses to reviewer comments on 1st submission, edited throughout resubmitted manuscript, and added key references and text. B.T.: proofed manuscript, designed tables, added references, made corrections to Discussion. M.M.: co-designed tables, added key references, and corrections to Introduction and Discussion of original and resubmitted manuscripts. S.A.C.: contributed references, wrote section on coronary spasm, and made corrections to original submission. N.T.: detailed proofing of all aspects of original manuscript and made important corrections to original submission text. A.T.: added important references and text to original and resubmitted manuscripts. A.D.A.: added important elements to Discussion section of original and resubmitted manuscript. N.B.: wrote several sections of original and resubmitted manuscripts. E.A.A.: conceived and directed project, rewrote multiple sections of original and resubmitted manuscript, and delegated work distribution of co-authors. 


\section{References}

1 Godwin JD 2nd. Carcinoid tumors. An analysis of 2,837 cases. Cancer. 1975 Aug;36(2): 560-9.

2 Pellikka PA, Tajik AJ, Khandheria BK, Seward JB, Callahan JA, Pitot HC, et al. Carcinoid heart disease. Clinical and echocardiographic spectrum in 74 patients. Circulation. 1993 Apr;87(4):1188-96.

3 Kulke MH, Mayer RJ. Carcinoid tumors. N Engl J Med. 1999 Mar;340(11):858-68.

4 Mawe GM, Hoffman JM. Serotonin signalling in the gut-functions, dysfunctions and therapeutic targets. Nat Rev Gastroenterol Hepatol. 2013 Aug;10(8):473-86.

5 Bhattacharyya S, Davar J, Dreyfus G, Caplin ME. Carcinoid heart disease. Circulation. 2007 Dec;116(24):2860-5.

6 Dobson R, Burgess MI, Pritchard DM, Cuthbertson DJ. The clinical presentation and management of carcinoid heart disease. Int J Cardiol. 2014 Apr;173(1):29-32.

7 Zuetenhorst JM, Taal BG. Metastatic carcinoid tumors: a clinical review. Oncologist. 2005 Feb;10(2):123-31.

8 Hart EA, Meijs TA, Meijer RC, Dreijerink KM, Tesselaar ME, de Groot CA, et al. Carcinoid heart disease: a guide for screening and timing of surgical intervention. Neth Heart J. 2017 Sep;25(9):471-8.

9 Zuetenhorst JM, Bonfrer JM, Korse CM, Bakker $\mathrm{R}$, van Tinteren H, Taal BG. Carcinoid heart disease: the role of urinary 5-hydroxyindoleacetic acid excretion and plasma levels of atrial natriuretic peptide, transforming growth factor- $\beta$ and fibroblast growth factor. Cancer. 2003 Apr;97(7):1609-15.

10 Connolly HM, Schaff HV, Mullany CJ, Rubin J, Abel MD, Pellikka PA. Surgical management of left-sided carcinoid heart disease. Circulation. 2001 Sep;104(12 Suppl 1):I3640.

11 Chaowalit N, Connolly HM, Schaff HV, Webb MJ, Pellikka PA. Carcinoid heart disease associated with primary ovarian carcinoid tumor. Am J Cardiol. 2004 May;93(10): 1314-5.

12 Laskaratos FM, Rombouts K, Caplin M, Toumpanakis C, Thirlwell C, Mandair D. Neuroendocrine tumors and fibrosis: an unsolved mystery? Cancer. 2017 Dec;123(24): 4770-90.

13 Lundin L, Norheim I, Landelius J, Oberg K, Theodorsson-Norheim E. Carcinoid heart disease: relationship of circulating vasoactive substances to ultrasound-detectable cardiac abnormalities. Circulation. 1988 Feb;77(2): 264-9.

14 Simula DV, Edwards WD, Tazelaar HD, Connolly HM, Schaff HV. Surgical pathology of carcinoid heart disease: a study of 139 valves from 75 patients spanning 20 years. Mayo Clin Proc. 2002 Feb;77(2):139-47.

15 Waltenberger J, Lundin L, Oberg K, Wilander E, Miyazono K, Heldin CH, et al. Involvement of transforming growth factor- $\beta$ in the forma- tion of fibrotic lesions in carcinoid heart disease. Am J Pathol. 1993 Jan;142(1):71-8.

16 Grozinsky-Glasberg S, Grossman AB, Gross DJ. Carcinoid heart disease: from pathophysiology to treatment - 'something in the way it moves'. Neuroendocrinology. 2015;101(4): 263-73.

17 Jian B, Xu J, Connolly J, Savani RC, Narula N, Liang B, et al. Serotonin mechanisms in heart valve disease I: serotonin-induced up-regulation of transforming growth factor-betal via G-protein signal transduction in aortic valve interstitial cells. Am J Pathol. 2002 Dec; 161(6):2111-21.

18 Gustafsson BI, Tømmerås K, Nordrum I, Loennechen JP, Brunsvik A, Solligård E, et al. Long-term serotonin administration induces heart valve disease in rats. Circulation. 2005 Mar;111(12):1517-22.

19 Pandya UH, Pellikka PA, Enriquez-Sarano M, Edwards WD, Schaff HV, Connolly HM. Metastatic carcinoid tumor to the heart: echocardiographic-pathologic study of 11 patients. J Am Coll Cardiol. 2002 Oct;40(7): 1328-32.

20 Eapen DJ, Clements S Jr, Block P, Sperling L. Metastatic carcinoid disease inducing coronary vasospasm. Tex Heart Inst J. 2012;39(1): 76-8.

21 Hergovich N, Aigner M, Eichler HG, Entlicher J, Drucker C, Jilma B. Paroxetine decreases platelet serotonin storage and platelet function in human beings. Clin Pharmacol Ther. 2000 Oct;68(4):435-42.

22 Bourgault C, Bergeron S, Bogaty P, Poirier P. A most unusual acute coronary syndrome. Can J Cardiol. 2006 Apr;22(5):429-32.

23 Bhattacharyya S, Toumpanakis C, Burke M, Taylor AM, Caplin ME, Davar J. Features of carcinoid heart disease identified by 2 - and 3-dimensional echocardiography and cardiac MRI. Circ Cardiovasc Imaging. 2010 Jan;3(1): 103-11.

24 Meurice J, Boulé S, Deswarte G, Brigadeau F, Modine T. Solitary atrial myocardial metastasis revealing ileal neuroendocrine carcinoma. Cardiovasc Pathol. 2012 Jul-Aug;21(4):355-7.

25 Bhattacharyya S, Toumpanakis C, Caplin ME, Davar J. Analysis of 150 patients with carcinoid syndrome seen in a single year at one institution in the first decade of the twentyfirst century. Am J Cardiol. 2008 Feb;101(3): 378-81.

26 Fox DJ, Khattar RS. Carcinoid heart disease: Presentation, diagnosis, and management. Heart. 2004 Oct;90(10):1224-8.

27 Rupp AB, Ahmadjee A, Morshedzadeh JH, Ranjan R. Carcinoid Syndrome-Induced Ventricular Tachycardia. Case Rep Cardiol. 2016;2016:9142598.

28 Tappin S, Brown P, Ferasin L. An intestinal neuroendocrine tumour associated with paroxysmal ventricular tachycardia and melaena in a 10-year-old boxer. J Small Anim Pract. 2008 Jan;49(1):33-7.
29 Dobson R, Burgess MI, Valle JW, Pritchard DM, Vora J, Wong C, et al. Serial surveillance of carcinoid heart disease: factors associated with echocardiographic progression and mortality. Br J Cancer. 2014 Oct;111(9): 1703-9.

30 Askew JW, Connolly HM. Carcinoid valve disease. Curr Treat Options Cardiovasc Med. 2013 Oct;15(5):544-55.

31 Davar J, Connolly HM, Caplin ME, et al. Diagnosing and managing carcinoid heart disease in patients with neuroendocrine tumors: an expert statement. J Am Coll Cardiol. 2017 Mar;69(10):1288-304.

32 Feldman JM, Lee EM. Serotonin content of foods: effect on urinary excretion of 5-hydroxyindoleacetic acid. Am J Clin Nutr. 1985 Oct;42(4):639-43.

33 Allen KR, Degg TJ, Anthoney DA, FitzroySmith D. Monitoring the treatment of carcinoid disease using blood serotonin and plasma 5-hydroxyindoleacetic acid: three case examples. Ann Clin Biochem. 2007 May;44(Pt 3):300-7.

34 Maurer-Spurej E, Pittendreigh C, Solomons $\mathrm{K}$. The influence of selective serotonin reuptake inhibitors on human platelet serotonin. Thromb Haemost. 2004 Jan;91(1):119-28.

35 Bhattacharyya S, Toumpanakis C, Caplin ME, Davar J. Usefulness of N-terminal pro-brain natriuretic peptide as a biomarker of the presence of carcinoid heart disease. Am J Cardiol. 2008 Oct;102(7):938-42.

36 Dobson R, Burgess MI, Banks M, Pritchard DM, Vora J, Valle JW, et al. The association of a panel of biomarkers with the presence and severity of carcinoid heart disease: a crosssectional study. PLoS One. 2013 Sep; 8(9):e73679.

37 Modlin IM, Oberg K, Chung DC, Jensen RT, de Herder WW, Thakker RV, et al. Gastroenteropancreatic neuroendocrine tumours. Lancet Oncol. 2008 Jan;9(1):61-72.

38 Kanakis G, Kaltsas G. Biochemical markers for gastroenteropancreatic neuroendocrine tumours (GEP-NETs). Best Pract Res Clin Gastroenterol. 2012 Dec;26(6):791-802.

39 Kidd M, Bodei L, Modlin IM. Chromogranin A: any relevance in neuroendocrine tumors? Curr Opin Endocrinol Diabetes Obes. 2016 Feb;23(1):28-37.

40 Palaniswamy C, Frishman WH, Aronow WS. Carcinoid heart disease. Cardiol Rev. 2012 Jul-Aug;20(4):167-76.

41 Bradette S, Papas K, Pressacco J. Imaging features of carcinoid heart disease. Can Assoc Radiol J. 2014 Aug;65(3):214-7.

42 Beri N, Farid A, Galkin M, Lewis W, Amsterdam E. Diagnostic dilemma: carcinoid syndrome. Am J Med. 2018 Oct;131(10): e405-7.

43 Ram P, Penalver JL, Lo KB, Rangaswami J, Pressman GS. Carcinoid heart disease: review of current knowledge. Tex Heart Inst J. 2019 Feb;46(1):21-7. 
44 Öberg KE, Reubi JC, Kwekkeboom DJ, Krenning EP. Role of somatostatins in gastroenteropancreatic neuroendocrine tumor development and therapy. Gastroenterology. 2010 Sep;139(3):742-53, 753.e1.

45 Kvols LK, Reubi JC, Horisberger U, Moertel CG, Rubin J, Charboneau JW. The presence of somatostatin receptors in malignant neuroendocrine tumor tissue predicts responsiveness to octreotide. Yale J Biol Med. 1992 Sep-Oct;65(5):505-18.

46 de Herder WW, Hofland LJ, van der Lely AJ, Lamberts SW. Somatostatin receptors in gastroentero-pancreatic neuroendocrine tumours. Endocr Relat Cancer. 2003 Dec;10(4): 451-8.

47 Pavel M, Benavent M, Perros P. Telotristat ethyl in carcinoid syndrome: safety and efficacy results of an open-label extension of the telecast phase 3 clinical trial. Pancreas. 2018; 47(3):350.

48 Kulke MH, Hörsch D, Caplin ME, Anthony LB, Bergsland E, Öberg K, et al. Telotristat ethyl, a tryptophan hydroxylase inhibitor for the treatment of carcinoid syndrome. J Clin Oncol. 2017 Jan;35(1):14-23.

49 Yao JC, Fazio N, Singh S, Buzzoni R, Carnaghi C, Wolin E, et al.; RAD001 in Advanced Neuroendocrine Tumours, Fourth Trial (RADIANT-4) Study Group. Everolimus for the treatment of advanced, non-functional neuroendocrine tumours of the lung or gastrointestinal tract (RADIANT-4): a randomised, placebo-controlled, phase 3 study. Lancet. 2016 Mar;387(10022):968-77.

50 Wolin EM. The expanding role of somatostatin analogs in the management of neuroendocrine tumors. Gastrointest Cancer Res. 2012 Sep;5(5):161-8.

51 Pavel ME, Baudin E, Öberg KE, Hainsworth JD, Voi M, Rouyrre N, et al. Efficacy of everolimus plus octreotide LAR in patients with advanced neuroendocrine tumor and carcinoid syndrome: final overall survival from the randomized, placebo-controlled phase 3 RADIANT-2 study. Ann Oncol. 2019 Dec;30(12): 2010.

52 Lillegard JB, Fisher JE, Mckenzie TJ, Que FG, Farnell MB, Kendrick ML, et al. Hepatic resection for the carcinoid syndrome in patients with severe carcinoid heart disease: does valve replacement permit safe hepatic resection? J Am Coll Surg. 2011 Jul;213(1):130-6.

53 Yancy CW, Jessup M, Bozkurt B, Butler J, Casey DE Jr, Drazner MH, et al. 2013 ACCF/ AHA guideline for the management of heart failure: executive summary: a report of the American College of Cardiology Foundation/ American Heart Association Task Force on practice guidelines. Circulation. 2013 Oct; 128(16):1810-52.

54 Nishimura RA, Otto CM, Bonow RO, et al. 2014 AHA/ACC guideline for the management of patients with valvular heart disease: Executive summary: a report of the American College of Cardiology/American Heart Association Task Force on Practice Guidelines. Circulation. 2014 Jun 10;129(23):2440-92.

55 Bernheim AM, Connolly HM, Hobday TJ, Abel MD, Pellikka PA. Carcinoid heart disease. Prog Cardiovasc Dis. 2007 May-Jun; 49(6):439-51.

56 Hassan SA, Banchs J, Iliescu C, Dasari A, Lopez-Mattei J, Yusuf SW. Carcinoid heart disease. Heart. 2017 Oct;103(19):1488-95.

57 Møller JE, Connolly HM, Rubin J, Seward JB, Modesto K, Pellikka PA. Factors associated with progression of carcinoid heart disease. $\mathrm{N}$ Engl J Med. 2003 Mar;348(11):1005-15.

58 Denney WD, Kemp WE Jr, Anthony LB, Oates JA, Byrd BF 3rd. Echocardiographic and biochemical evaluation of the development and progression of carcinoid heart disease. J Am Coll Cardiol. 1998 Oct;32(4):101722.

59 Bhattacharyya S, Toumpanakis C, Chilkunda D, Caplin ME, Davar J. Risk factors for the development and progression of carcinoid heart disease. Am J Cardiol. 2011 Apr;107(8): 1221-6.

60 Connolly HM, Schaff HV, Abel MD, Rubin J, Askew JW, Li Z, et al. Early and late outcomes of surgical treatment in carcinoid heart disease. J Am Coll Cardiol. 2015 Nov;66(20): 2189-96.

61 Manoly I, McAnelly SL, Sriskandarajah S, McLaughlin KE. Prognosis of patients with carcinoid heart disease after valvular surgery. Interact Cardiovasc Thorac Surg. 2014 Aug; 19(2):302-5.
62 Bhattacharyya S, Raja SG, Toumpanakis C, Caplin ME, Dreyfus GD, Davar J. Outcomes, risks and complications of cardiac surgery for carcinoid heart disease. Eur J Cardiothorac Surg. 2011 Jul;40(1):168-72.

63 Mota JM, Sousa LG, Riechelmann RP. Complications from carcinoid syndrome: review of the current evidence. Ecancermedicalscience. 2016 Aug; 10:662.

64 Ridker PM, Chertow GM, Karlson EW, Neish AS, Schoen FJ. Bioprosthetic tricuspid valve stenosis associated with extensive plaque deposition in carcinoid heart disease. Am Heart J. 1991 Jun;121(6 Pt 1):1835-8.

65 Khan JN, Doshi SN, Rooney SJ, Bhabra MS, Steeds RP. Transcatheter pulmonary and tricuspid valve-in-valve replacement for bioprosthesis degeneration in carcinoid heart disease. Eur Heart J Cardiovasc Imaging. 2016 Jan;17(1):114.

66 Heidecker B, Moore P, Bergsland EK, Merrick SH, Rao RK. Transcatheter pulmonic valve replacement in carcinoid heart disease. Eur Heart J Cardiovasc Imaging. 2015 Sep;16(9): 1046.

67 Bekaii-Saab TS, Roda JM, Guenterberg KD, Ramaswamy B, Young DC, Ferketich AK, et al. A phase I trial of paclitaxel and trastuzumab in combination with interleukin-12 in patients with HER2/neu-expressing malignancies. Mol Cancer Ther. 2009 Nov;8(11):2983-91.

68 Wolin EM, Jarzab B, Eriksson B, Walter T, Toumpanakis C, Morse MA, et al. Phase III study of pasireotide long-acting release in patients with metastatic neuroendocrine tumors and carcinoid symptoms refractory to available somatostatin analogues. Drug Des Devel Ther. 2015 Sep;9:5075-86.

69 Janson ET, Oberg K. Long-term management of the carcinoid syndrome. Treatment with octreotide alone and in combination with alphainterferon. Acta Oncol. 1993;32(2):225-9.

70 Maqsood MH, Tameez Ud Din A, Khan AH. Neuroendocrine herapy with lutetium-177: a literature review. Cureus. 2019 Jan;11(1): e3986.

71 Jia Z, Wang W. Yttrium-90 radioembolization for unresectable metastatic neuroendocrine liver tumor: a systematic review. Eur J Radiol. 2018 Mar;100:23-9. 